\title{
Total Synthesis of Madindolines, Potent Selective Inhibitors of Interleukine 6, Novel Bioactive Microbial Metabolites
}

\author{
Toshiaki Sunazuka, Tomoyasu Hirose, and Satoshi Ōmura \\ Kitasato Institute for Life Sciences, Kitasato University, and The \\ Kitasato Institute,
}

Received July 1, 2005

\begin{abstract}
The first total synthesis of madindolines A and B, potent selective inhibitors of interleukin 6 (IL-6), has been achieved by stereoselective aldol reaction, ring-closing metathesis, reductive amination, followed by an asymmetric oxidative ring closure of indole, and resulted in determination of their absolute stereochemistries. We have further developed a more efficient second-generation synthesis, which is suitable for gram-scale preparation of these compounds, by stereoselective acylation of ester 34, followed by an intramolecular acylation of ester 32 with allylsilane $\left(19 \%\right.$ yield over 9 steps). Synthetic $\left[{ }^{3} \mathrm{H}\right]$-madindoline A bound to gp-130, selectively. Furthermore, synthetic madindoline A markedly inhibited osteoclastogenesis in vitro and bone resorption in ovariectomized mice in vivo.
\end{abstract}

\section{Introduction}

Bioactive natural products produced by microbes have limitless potential in pharmaceutical applications, and the organic synthesis of such products as lead compounds will result in the creation of new and widely useful pharmaceutical products.

With a focus on the drug discovery process, the Kitasato Institute is using cutting-edge, unique screening techniques to discover useful bioactive natural products from microbial metabolites. These novel natural products have distinctive structures and attractive bioactivities. ${ }^{1,2}$

The key challenge in synthetic organic chemistry is how to more efficiently synthesize target compounds with unique, novel molecular skeletons using short process pathways. The construction of novel molecular skeletons necessitates the development of new synthetic strategies and key reactions, which leads to further progress in synthetic organic chemistry (Figure 1).

If efficient synthetic methods can be established, it will be possible to quantitatively supply natural products that are presently only naturally available in trace amounts, and will contribute to a more thorough elucidation of their bioactivities. In addition, it will become possible to determine the relative and absolute configuration and structures of compounds, using synthetic techniques, for which only trace amounts can be extracted from natural sources. Furthermore, use of newly developed molecular skeleton construction methods will allow the creation of a wide range of analogs, thereby leading to the production of compounds with properties that surpass those found in nature and heralding the promise of bioactivity. Hence, the discovery of bioactive natural products with novel molecular skeletons will lead to advances in synthetic organic chemistry, that are dynamically related to the elucidation and development of bioactive materials (Figure 1).

Target compounds of new natural products may only be available from natural sources in trace amounts, so that the Kitasato Institute has built on the above concepts to develop efficient, rational, and highly flexible construction methods

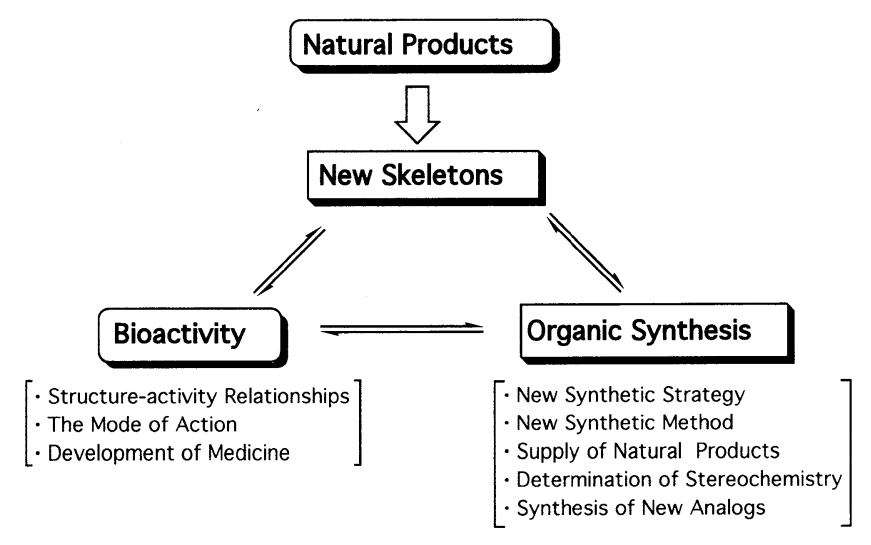

Figure 1

for the production of compounds with novel molecular skeletons and useful bioactivities. To date, 20 types of bioactive natural products have been successfully synthesized. The research program also calls for the application of established methods to synthesize related compounds, elucidating their structure-activity relationships, and contributing to the creation of improved bioactive compounds. In this article, the total synthesis of madindolines, selective inhibitors of interleukin 6 (IL-6), is discussed.

It is well known that cytokines not only contribute to homeostasis via immune responses and biological defense, but they also are involved in cancer, inflammation, allergies, and autoimmune diseases. IL-6 is a multifunctional cytokine involved in control of antibody production, $\mathrm{T}$ cell activation, hematopoiesis and acute responses, and uncontrolled IL-6 activity causing various serious diseases. ${ }^{3}$ It has been reported that excess IL-6 production is closely associated with cancer cachexia, ${ }^{4}$ Castleman's disease, ${ }^{5}$ rheumatoid arthritis, ${ }^{6}$ hypercalcemia, ${ }^{7}$ and multiple myeloma. ${ }^{8}$ No effective therapeutic drugs for these diseases have been developed, but a low molecular weight compound should be developed for therapeutic use that modulates function of this cytokine by a new action mechanism. The IL-6 receptor (IL-6R) system consists of two components: a ligand-binding $80-\mathrm{kDa}$ glyco- 
protein chain (IL-6R) and a signal-transducing glycoprotein 130 (gp130). IL-6 induces gp130 homodimerization after binding to the specific receptor, which leads to activation of the Janus kinase (JAK)/signal transducer and activator of transcription (STAT) signal transduction pathway. Accordingly, substances that inhibit this cascade can be used as an IL-6-specific inhibitor. ${ }^{9}$

In 1996, we reported the isolation of novel indole alkaloids from the culture broth of Streptomyces nitrosporeus K93-0711, madindolines A (+)-1 and B (+)-2 (Figure 2), as selective inhibitors of IL-6. ${ }^{10,11}$ The biological activity profiles of (+)-1 and (+)-2 were exceptional. Both $(+)-1$ and $(+)-2$ specifically inhibited the growth of the IL-6-dependent MH60 cell line $\left(\mathrm{IC}_{50}\right.$ values of $8 \mu \mathrm{M}$ and $30 \mu \mathrm{M}$, respectively), ${ }^{10}$ but they did not affect the IL-6-independent MH60 cell line. More detailed biological studies showed that (+)-1 dose-dependently suppressed IL-6 and IL-11-induced osteoclastogenesis. However, further studies on their biological properties were not possible, because the madindolines were no longer available from natural sources due to mutation of the bacterial strain. Thus, the madindolines have been only available via total synthesis.

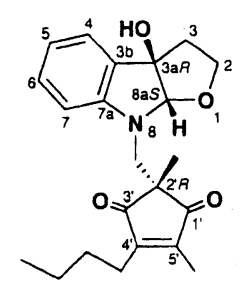

(+)-Madindoline A (+)-1

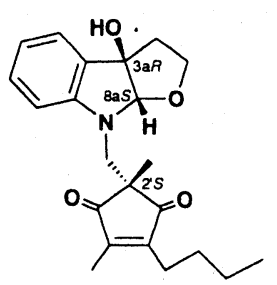

(+)-Madindoline B (+)-2
Figure 2. Structures of (+)-madindolines A (1) and B (2).

Madindolines are comprised of an unusual 3a-hydroxyfuroindoline ring connected at the nitrogen via a methylene bridge to the cyclopentene-1,3-dione ring. The planar structures of 1 and $\mathbf{2}$ were assigned by detailed 1-and 2-D NMR studies, in conjunction with IR, UV and mass data, but the relative and absolute configurations have remained undefined. ${ }^{11}$ They were stereoisomers at the $\mathrm{C}-2^{\prime}$ position. Due to the promising biological activity and novel structures of madindolines, we have focused on the total synthesis of these compounds to determine their stereochemistry and to supply the materials. So far, four total syntheses of madindolines, including our first- and second-generation syntheses, have been reported. ${ }^{12}$ Herein, we report the development of our total syntheses of madindolines.

\section{The First Generation of Total Synthesis of Madindo- lines $A$ and $B$}

For the enantioselective total synthesis, there are three problems (Figure 3). First is an asymmetric synthesis of the $3 a$-hydroxyfuroindoline ring. Second is the coupling reaction between a low reactive nitrogen on the $3 \mathrm{a}$-hydroxyfuroindoline and a cyclopentene ring. Third is a stereoselective construction of a quaternary carbon on the cyclopentene ring.

\subsection{Asymmetric Synthesis of Both Enantiomers of}

\section{3a-Hydroxyfuroindoline}

Before we embarked upon the first total synthesis and determination of the absolute stereochemistry of madindo-

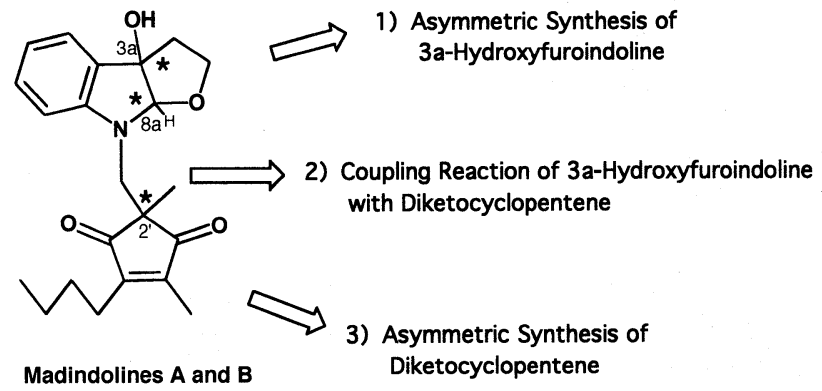

Figure 3. Problems for the enantioselective synthesis of $(+)$-madindolines A and B.

lines, it was necessary to demonstrate that optically pure 3a-hydroxyfuroindoline 4 can be easily prepared from commercially available compounds. Based on our observation that $m$-CPBA oxidation of tryptophol $\mathbf{3}$ afforded racemic $3 \mathrm{a}$-hydroxyfuroindoline 4 in $75 \%$ yield, we expected that asymmetric oxidative ring-closure of $\mathbf{3}$ would be possible by a combination of suitable asymmetric inducers with an oxidative reagent. Thus, we tried to establish the protocol by taking advantage of the Sharpless asymmetric epoxidation. ${ }^{13}$ In the initial attempts we examined the reaction under the standard Sharpless epoxidation conditions, the results of which are summarized in Table 1 . To obtain high enantioselectivities, low concentration of the substrate 3 with a stoichiometric oxidant is required for relatively small-scale production, but for large-scale reactions, short reaction time and lower temperature are preferred rather than the dilute conditions. For instance, dilute and stoichiometric conditions for a small-scale $(70 \mathrm{mg})$ reaction generated highly optically active (-) $\mathbf{- 4}$ in $72 \%$ yield (entry 2); however, the catalytic protocol proved less effective (e.g., $37 \%$ yield; $28 \%$ ee; entry 4 ), and the reaction with $0.1 \mathrm{M}$ at $-40{ }^{\circ} \mathrm{C}$ for a large-scale production $(7.5 \mathrm{~g})$ gave $(-)-4$ in $55 \%$ yield without a decrease in enantioselectivity (entry 7). We suspect that this is caused by difficulty in maintaining the temperature within the reaction mixture when dilute conditions are used for large-scale production. Finally, use of (+)-DIPT instead of (-)-DIPT afforded the enantiomer $(+)-\mathbf{4}$ with high enantioselectivity and with a similarly good yield. Thus, the reaction protocol uan provide both enantiomers of 3 a-hydroxyfuroindoline with high optical purities (Scheme 1). This is the first example for the asymmetric oxidative reaction with the achiral indole compound.

To determine the absolute stereochemistry, $(-\mathbf{-} \mathbf{- 4}$ was treated with $\mathrm{MeI}$ followed by esterification with (-)-MTPA to produce ester $(\mathbf{-}) \mathbf{- 5}$ as a light yellow crystal. Single-crystal X-ray diffraction for $(-)-\mathbf{5}$ was performed to confirm the stereochemistry of $(\mathbf{-}-\mathbf{- 4}$.

Based on the proposed mechanism by Saito et al. for the preparation of racemic 4 using singlet oxygen, ${ }^{14}$ this oxidative ring-closure likely occurs by an electrophilic attack of the peroxide at the 3-position of the indole ring, followed by ring-closure between the imine carbon and the primary alcohol (Scheme 1).

\subsection{N-Alkylation of a Model System}

Next, we tried to establish the reaction conditions for coupling of (-)-4 with cyclopentene-1,3-dione units to construct the whole madindoline skeleton. We examined reductive amination ${ }^{15}$ of simple aldehydes with $(-)-4$ (Scheme 2 ). 
Table 1. Results of asymmetric oxidative ring-closure of tryptophol (3)

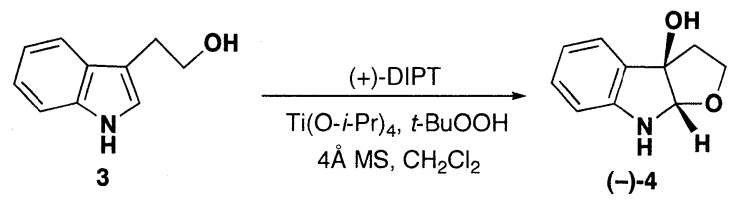

\begin{tabular}{|c|c|c|c|c|c|c|c|c|}
\hline \multirow[t]{2}{*}{ Entry } & \multicolumn{2}{|c|}{ Reagents $(e q)^{a}$} & \multirow{2}{*}{$\begin{array}{l}\text { Concentration of } \\
3 \text { in } \mathrm{CH}_{2} \mathrm{Cl}_{2} \text { (M) }\end{array}$} & \multirow{2}{*}{$\begin{array}{l}\text { Temp. } \\
\left({ }^{\circ} \mathrm{C}\right)\end{array}$} & \multirow{2}{*}{$\begin{array}{l}\text { Time } \\
\text { (h) }\end{array}$} & \multirow{2}{*}{$\begin{array}{l}\text { Scale } \\
\text { for } 3\end{array}$} & \multirow{2}{*}{$\begin{array}{r}\text { Yield }^{b} \\
(\%)\end{array}$} & \multirow{2}{*}{$\begin{array}{l}\% e^{\circ} \text { of } \\
\text { Product }\end{array}$} \\
\hline & $\mathrm{Ti}(\mathrm{O}-\mathrm{i}-\mathrm{F}$ & +)-DIPT & & & & & & \\
\hline 1 & 1.0 & 1.2 & 0.4 & -20 & 3 & $500 \mathrm{mg}$ & 36 & 69 \\
\hline 2 & 1.0 & 1.2 & 0.01 & -20 & 6 & $70 \mathrm{mg}$ & 72 & 99 \\
\hline 3 & 1.0 & 1.2 & 0.01 & -20 & 5 & $1.0 \mathrm{~g}$ & 67 & 73 \\
\hline 4 & 0.25 & 0.30 & 0.01 & -20 & 48 & $70 \mathrm{mg}$ & 37 & 28 \\
\hline 5 & 1.0 & 1.2. & 0.1 & -40 & 4 & $1.0 \mathrm{~g}$ & 60 & 84 \\
\hline 6 & 1.8 & 2.0 & 0.1 & -40 & 2 & $1.0 \mathrm{~g}$ & 56 & $>99$ \\
\hline 7 & 1.8 & 2.0 & 0.1 & -40 & 2 & $7.5 \mathrm{~g}$ & 55 & 99 \\
\hline
\end{tabular}

${ }^{2}$ All reactions were carried out with $\mathrm{t}-\mathrm{BuOOH}(2.5 \mathrm{eq})$ in $4 \AA$-molecular sieves. ${ }^{\circ}$ Yields were based on pure materials isolated by chromatography on $\mathrm{SiO}_{2} .{ }^{\circ} \mathrm{The}$ ee of the product was determined by HPLC analysis (column, DAICEL Chiralcel $(46 \times 250 \mathrm{~mm})$; UV at $254 \mathrm{~nm} ; 0.35 \mathrm{~mL} / \mathrm{min} ; 0^{\circ} \mathrm{C}$; solvent, $9 \% 2$-propanol in hexane, $\mathrm{Rt}=70.5 \mathrm{~min}$ ).

Scheme 1. Asymmetric synthesis of both enantiomers of 3a-hydroxyfuroindoline (4)

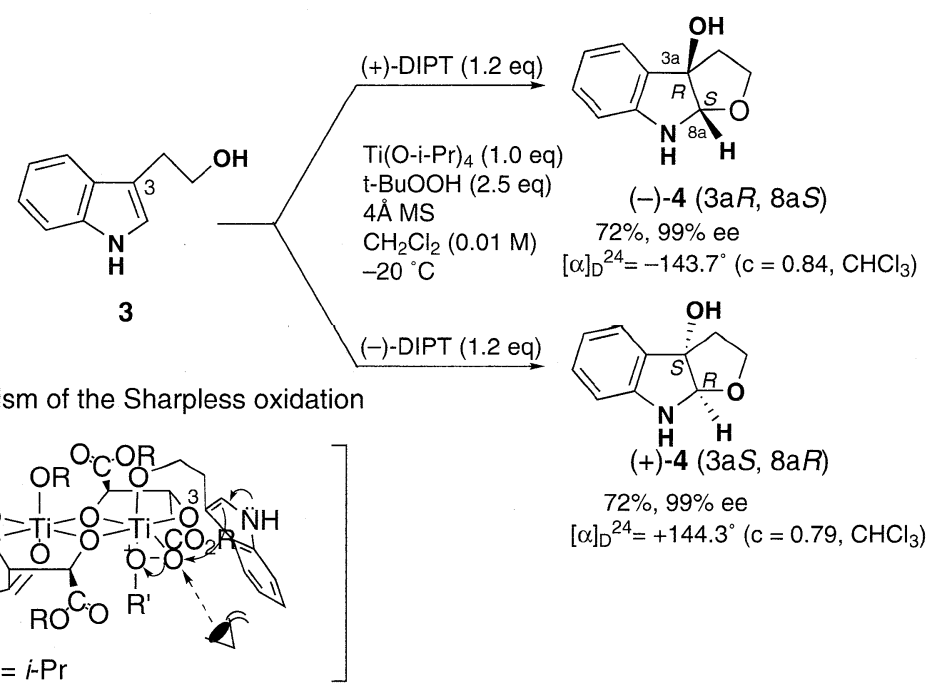

Amination of 2-methylpropanal with $(-)-4$ provided the $N$-isobutylindoline (-)-6 in moderate yield $(62 \%)$, whereas pivaroylaldehyde, carrying a quaternary center at the $\alpha$-position like a real coupling partner, did not produce the desired product but rather the undesired $N-t$-butyltryptophol 7 in

Scheme 2. Reductive amination of simple aldehydes with furoindoline (-)-4

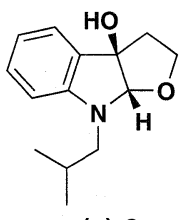

$(-)-6$

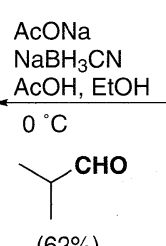

$(62 \%)$

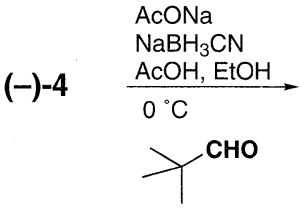

$(80 \%)$<smiles>CC(C)(C)Cn1cc(CCO)c2ccccc21</smiles>

7 high yield $(80 \%)$. Moreover, all attempts for $N$-alkylation of (-)-4 with a simple alkyl halide were unsuccessful under the conditions tested and produced mixtures of undesired products.

These results led us to try coupling with tryptophol $\mathbf{3}$, the precursor of $(-)^{-4}$, with a suitable aldehyde under reductive amination conditions. ${ }^{14}$ However, due to the high nucleophilicity of the 3-position of indole, standard reductive amination conditions furnished the undesired furoindoline $\mathbf{8}$ in $29 \%$ yield together with the desired $N$-alkylated indole 7 in $22 \%$ yield (Scheme 3).

To circumvent this problem, the indole 
Scheme 3. Reductive amination of pivaroyl aldehyde with tryptophol (3)

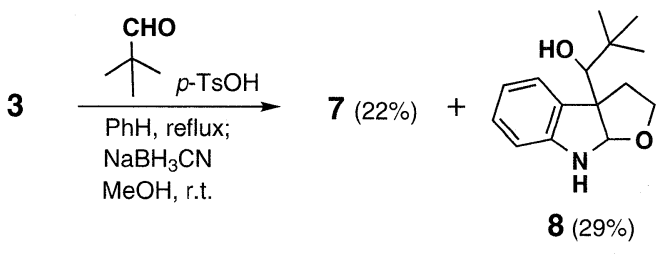

moiety was reduced to indoline $9^{16}$ in $100 \%$ yield to remove the nucleophilicity at the C3-position. Reductive amination ${ }^{17}$ was then carried out to produce $N$-alkylated indoline $\mathbf{1 0}$ in good yield (89\%). Oxidation of $\mathbf{1 0}$ with $\mathrm{MnO}_{2}{ }^{16}$ led to the desired product 7 in excellent yield (99\%) (Scheme 4). With this ability to convert indoline to indole, we were able to design a coupling reaction between the indole unit and sterically hindered aldehyde.

Scheme 4. Reductive amination with indoline
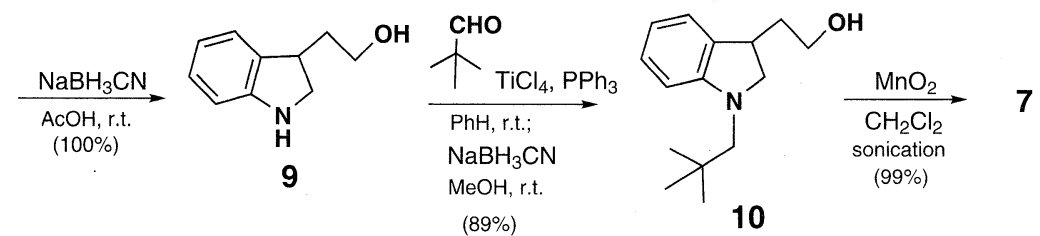

madindoline skeleton, thereby permitting establishment of the relative and absolute configurations of $\mathbf{1}$ and $\mathbf{2}$.

\subsection{Synthesis of the Cyclopentene Core}

The construction of the required cyclopentene core began with the Evans asymmetric aldol reaction of oxazolidinone $(+)-17^{19,20}$ with 2 -butylacrolein $\mathbf{1 6}$ to produce the aldol product in $81 \%$ yield with $>99 \%$ de, which was followed by methanolysis under basic conditions $(\mathrm{MeONa}$ in $\mathrm{MeOH})$, furnishing the $\beta$-hydroxyester (-)-15 in 91\% yield (Scheme 6). The Frater aldol protocol ${ }^{21}$ of $(-)-\mathbf{1 5}$ with methacrolein 14 furnished diene $\mathbf{1 3}$ as an inseparable mixture (mainly the $R$ configuration) in $54 \%$ (96\% based on recovered SM) yield. However, the ring-closing olefin metathesis (RCM) using the first-generation Grubbs reagent (cat. A) ${ }^{18}$ or the Schrock reagent (cat. B) ${ }^{18 a}$ to form cyclopentene $\mathbf{1 8}$ was unsuccessful. When the RCM was attempted with cat. $\mathbf{A}$ in any solvents, only the unreacted starting material and some unstable carbene complexes were observed. In the case of cat. B, substrate $\mathbf{1 3}$ could not survive under the reaction conditions. We reasoned that this RCM reaction would be suppressed by high steric hindrance between the methyl and butyl groups on the double bonds. To avoid this problem, we planned to introduce the butyl function on the double bond of cyclopentene after

\subsection{Retrosynthetic Analysis of Madindolines A and B}

Scheme 5 outlines our retrosynthetic strategy for madindolines. Having secured a viable asymmetric protocol to access the $3 \mathrm{a}$-hydroxyfuroindoline ring and an $\mathrm{N}$-alkylation protocol to yield $N$-alkyl indole, we envisioned the total synthesis of $\mathbf{1}$ and $\mathbf{2}$ to entail reductive coupling of aldehyde $\mathbf{1 2}$ with 3-(2-ethanol)-indoline 9 and oxidation of the indoline unit, followed by the stereocontrolled introduction of the 3a-hydroxyfuroindoline ring exploiting the Sharpless protocol. The synthetic strategy for the cyclic aldehyde 12 depends on the efficient ring formation from the linear diene $\mathbf{1 3}$ with Grubbs' ring-closing olefin metathesis reaction. ${ }^{18}$ We reasoned that 13 could be prepared from double-stereoselective aldol reactions. Importantly, this strategy was promising for controlled access to each of the possible stereoisomers of the

\section{the $\mathrm{RCM}$ reaction.}

To produce a cyclopentene substrate without a butyl group, stereoselective double aldol reactions from $(+)-\mathbf{1 7}$ with acrolein 19 and methacrolein 14 were carried out by a series of reactions analogous to Scheme 6 . The aldol reaction of (+)-17 with acrolein 19 proceeded in $89 \%$ yield with $>99 \%$ d.e. (Scheme 7); methanolysis afforded (+)-20 in $87 \%$ yield. Fráer's aldol protocol with methacrolein 14 furnished diene 21 in 70\% (97\% based on recovered SM) yield as a hardly separable diastereomeric mixture. To establish the relative stereochemistries of the components in 21 , the mixture was converted to the corresponding 1,3-acetonides $22 \mathbf{a}-\mathbf{c},{ }^{22}$ which were separated by flash chromatography. NOE analysis permitted stereochemical assignment.

Hydrolysis $^{23}$ of the major acetonide (+)-22a followed by

Scheme 5. Retrosynthesis of madindolines

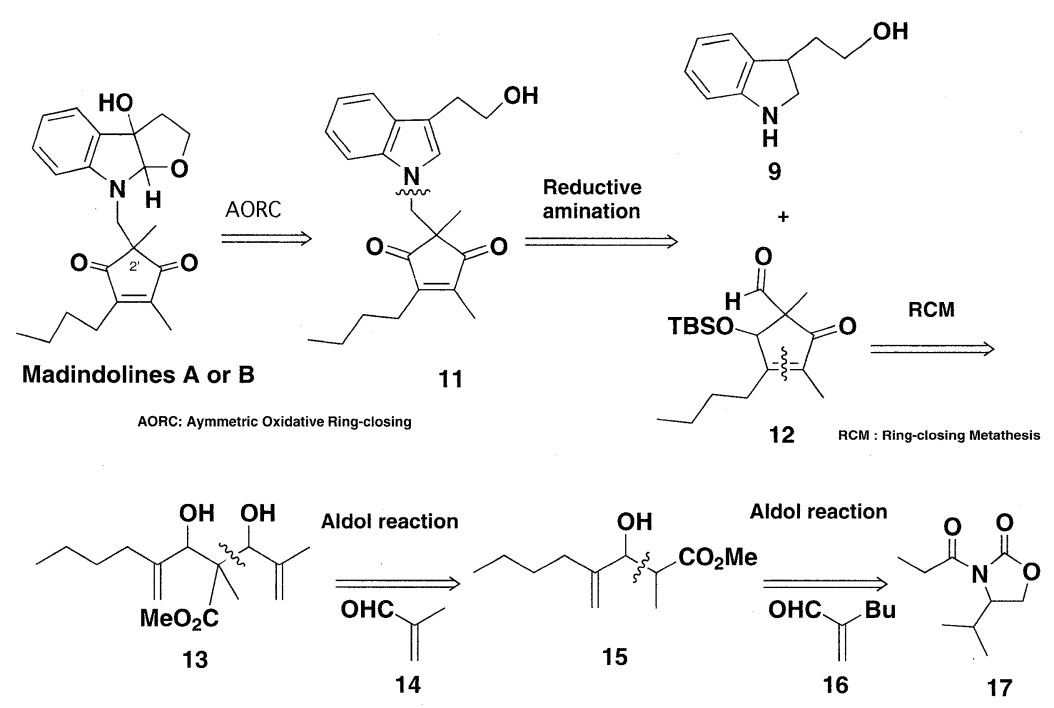


Scheme 6. Preparation of diene 13 and RCM

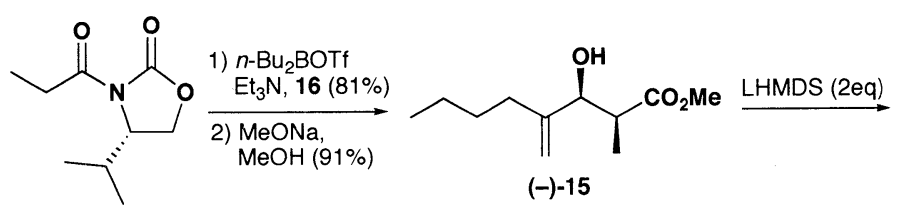

(+)-17<smiles>C=C(C)[C@H](O)[C@@H](O)[C@@H](O)C(=O)CCCCC</smiles>

13 (Mostly $R$ configuration)

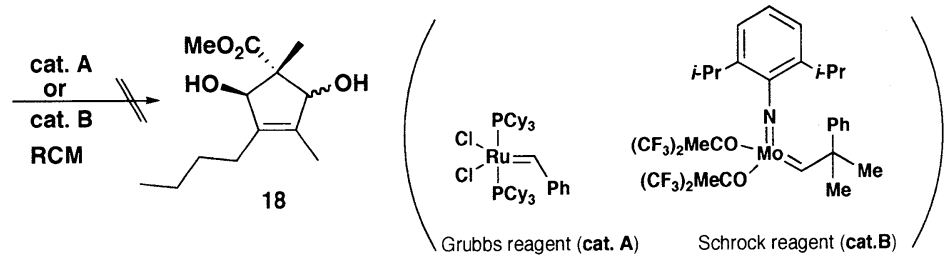

Scheme 7. Preparation of diene 21 and 22<smiles>CCC(=O)N1C(=O)OC[C@H]1C(C)C</smiles>

$(+)-17$

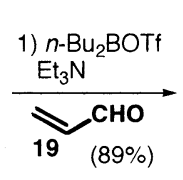

2) $\mathrm{MeONa}$

$\mathrm{MeOH}(87 \%)$

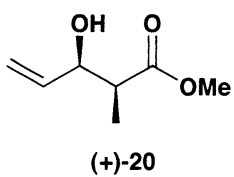

$(+)-20$

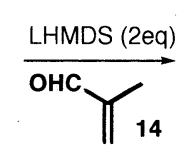

$(70 \%)$

Conversion yield

$97 \%$

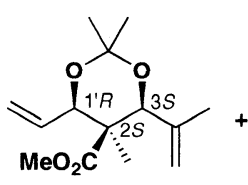

(+)-22a (54\%)
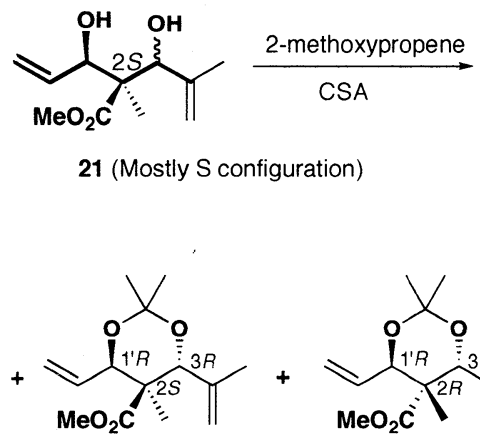

(+)-22b (18\%)

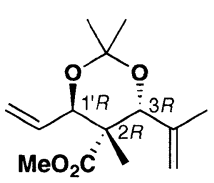

$(+)-22 c(11 \%)$
RCM of (+)-21a ( 0.2 eq. Grubbs catalyst, $\left.\mathrm{CH}_{2} \mathrm{Cl}_{2}, 40{ }^{\circ} \mathrm{C}\right)$ furnished cyclopentene $(-)-\mathbf{2 3}$ in $69 \%$ yield. Selective protection of the less hindered allylic alcohol with TBSOTf $(86 \%$ yield) followed by $\mathrm{MnO}_{2}$ oxidation provided (-)-24 in quantitative yield (Scheme 8). For material advancement, the diastereomeric mixture of diene $\mathbf{2 1}$ was subjected directly to the RCM, and selective protection of the less hindered hydroxyl group, oxidation and flash chromatography separation provided (-) $\mathbf{- 2 4}$ as a single diastereomer in $53 \%$ overall yield. Subsequent conjugate addition with $n-\mathrm{Bu}_{2} \mathrm{CuLi}^{24}$, followed by phenylselenylation of the derived enolate with $\mathrm{PhSeBr}$, and oxidative elimination using $\mathrm{H}_{2} \mathrm{O}_{2}$ under acidic conditions furnished a 1:1 mixture of exo:endo olefin isomers. Treatment of the mixture with $\mathrm{RhCl}_{3}{ }^{25}$ in aqueous EtOH converted the exo congener to the endo cyclopentenone (-)-26 in $\mathbf{7 3} \%$ overall yield from (-)-24.

2.5 Total Synthesis of the Madindolines A and B

Having prepared the madindoline cyclopentene fragment
(-) -26, the following steps were carried out to couple the indoline unit with the cyclopentene fragment and, thus, complete the total synthesis. As previously discussed, failure in the coupling of $3 \mathrm{a}$-hydroxyfuroindoline with cyclopentenedione led us to focus on the use of 3-(2-ethanol)-indoline 9 as a precursor of $3 \mathrm{a}$-hydroxyfuroindoline. To obtain the coupling partner, reduction of (-)-26 with $\mathrm{LiAlH}_{4}$, followed by Dess-Martin oxidation ${ }^{26}$ provided ketoaldehyde 27 (Scheme 9). However, 27 was found to be very unstable due to deformylation. Therefore, 27 was subjected to the reductive amination with indoline $\mathbf{2 8}$ without purification. Several reaction conditions were attempted for this reductive amination. However, all of them resulted in poor yields, and the best result obtained by $\mathrm{TiCl}_{4}$ treatment in benzene and $\mathrm{NaBH}_{3} \mathrm{CN}$ reduction in $\mathrm{MeOH}$ gave the desired product 29 in only $16 \%$ overall yield from $(-)-\mathbf{2 6}$.

This difficulty was probably associated with the instability of the aldehyde function due to the ketone group at the $\alpha$-carbon. To avoid this problem, (-)-26 was subjected to stereoselective reduction of the ketone group with $\mathrm{NaBH}_{4}$ and $\mathrm{CeCl}_{3}{ }^{27}$, silylation of the resulted allylic alcohol with $\mathrm{TBSCl}$ in the presence of $\mathrm{KH}$ and $18-$ crown $-6,{ }^{28}$ and DIBAL-H reduction of the ester group to produce the primary alcohol (+)-30 (74\% for the three steps), which is the precursor of the aldehyde. NOE analysis of (+)-30 allowed stereochemical assignment (Scheme 10). To this end, the Dess-Martin oxidation $^{26}$ of (+)-30 proceeded smoothly. The intermediate of an iminium salt was generated from aldehyde and 28 with $\mathrm{TiCl}_{4}$ in benzene, and then a solution of $\mathrm{NaBH}_{3} \mathrm{CN}$ in $\mathrm{MeOH}$ was directly added to the iminium solution to furnish the desired $N$-alkylindoline $\mathbf{3 1}$ as a diastereomeric mixture in 77\% yield from (+)-30 (96\% based on recovered (+)-30). Finally, all protecting groups were removed by TBAF in THF, followed, in turn, by selective TES protection of the primary hydroxy group with TESCl and $E t_{3} \mathrm{~N}$, oxidation of indoline and allyl alcohols with $\mathrm{MnO}_{2}$, and acid hydrolysis of the TES ether, producing indole $(+)-11$ in $69 \%$ yield from 31 .

In the final stage, we attempted the oxidative ring-closing reaction of (+)-11 under a modified Sharpless asymmetric 
Scheme 8. Synthesis of cyclopentenone (-)-26

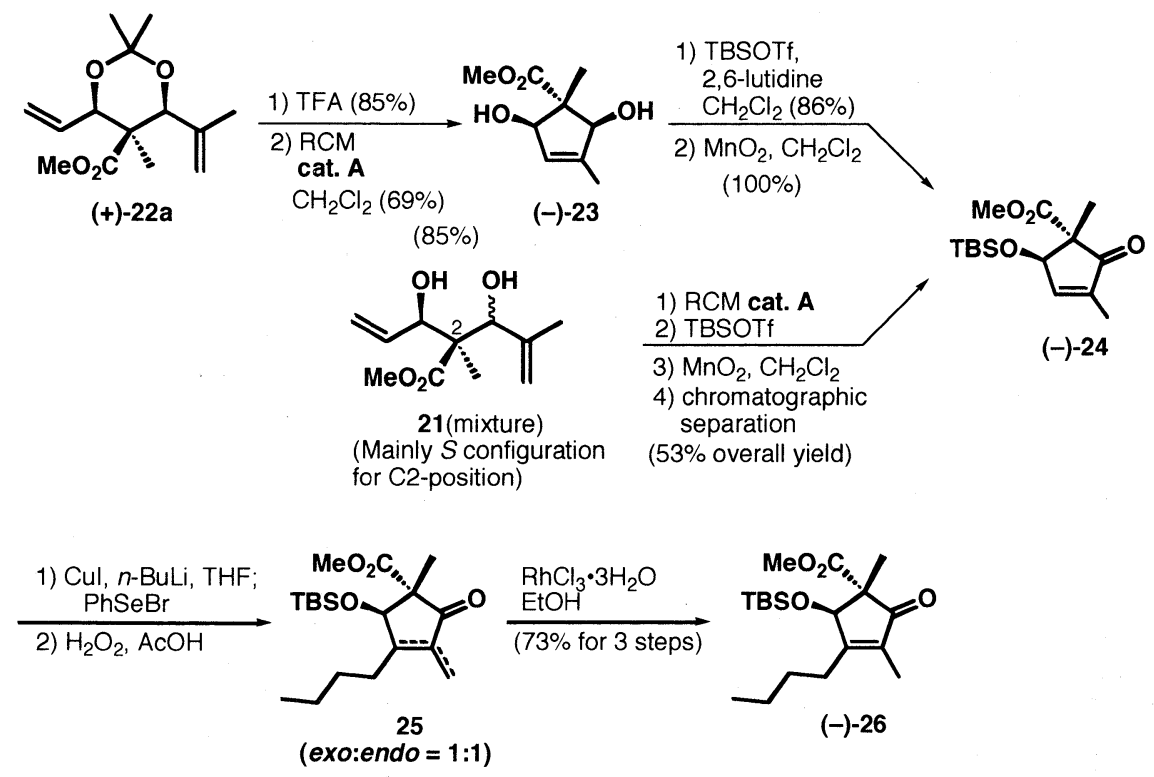

Scheme 9. Reductive amination (procedure 1)

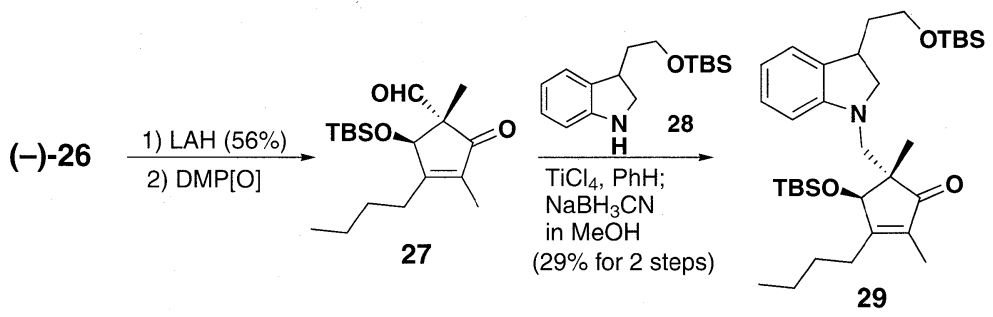

Scheme 10. Reductive amination (procedure 2) and preparation of $N$-alkylindole $(\mathbf{+}) \mathbf{- 1 1}$
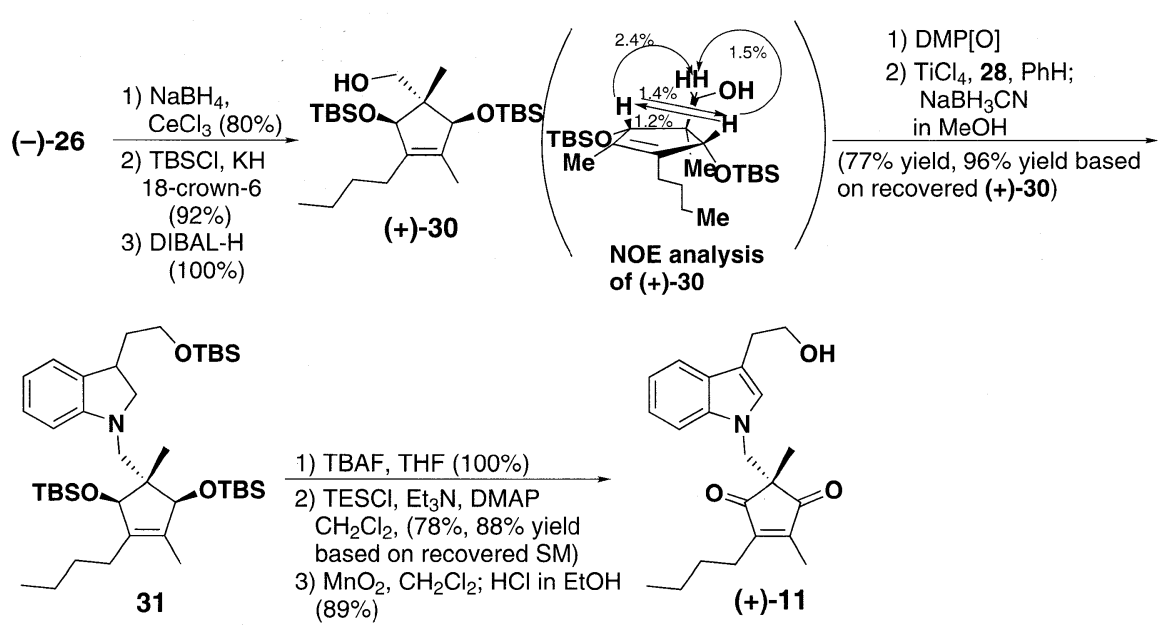

epoxidation protocol using $(+)$-diethyl tartrate (DET). This yielded (+)-madindoline A (+)-1 and (-)-madindoline B $(-)-2$ in $45 \%$ yield in a 2.2:1 ratio (Scheme 11). Use of the $(-)$-DET ligand was also attempted and (+)-1 and (-)-2 were produced in $49 \%$ yield with 1:2.3 ratio. In the case of this substrate, high diastereoselectivity was not observed. This was presumably due to steric hindrance by the bulky substitution on the nitrogen that interferes with the access of the Sharpless catalyst to the reaction site.

The synthetic crystalline (+)-madindoline A (+)-1 was identical in all respects with natural (+)-1 $\left[400 \mathrm{MHz}{ }^{1} \mathrm{H}\right.$ and $100 \mathrm{MHz}{ }^{13} \mathrm{C}$ NMR, IR, HRMS, optical rotation, mp, mmp, and TLC]. Synthetic (-)-madindoline B (-)-2 was also identical with natural $(+)$-madindoline $B(+)-2$ in all respects, except for the chiroptical properties. Thus, $(-)$-madindoline $\mathrm{B}(-)-\mathbf{2}$ is the enantiomer of natural $(+)-\mathbf{2}$. Furthermore, confirmation of the relative and absolute stereochemistry in (+)-1 and (+)-2 was achieved by single crystal X-ray analysis of synthetic (+)-1 as shown in Figure 4. Based on these results, we were able to reveal the absolute stereochemistries of madindolines as shown in Figure 2, and show that these compounds are diastereomers of the $\mathrm{C}^{2}$ position. In summary, the first asymmetric total synthesis of madindolines $\mathrm{A}$ and $\mathrm{B}$ has been achieved via a 19 linear 
Scheme 11. Oxidative ring closing reaction of $(+)-11$
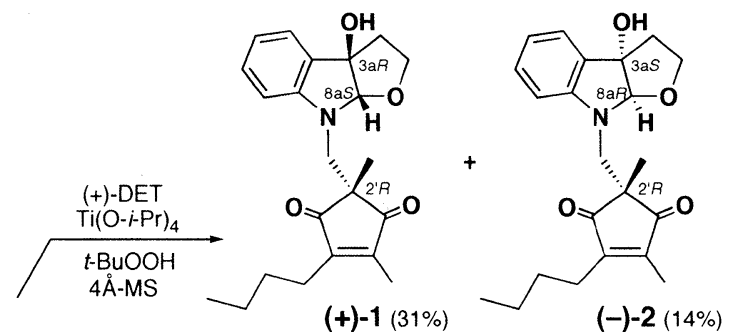

$(+)-11$

$(+)-1(31 \%)$

$(-)-2(14 \%)$

2.2

1

tuted cyclopentenedione core. In addition, the final oxidative ring-closure is not highly stereoselective. In this section, we report a more efficient and practical total synthesis of (+)-madindolines A (+)-1 and B (+)-2. The retrosynthesic analysis of the second-generation synthesis is outlined in Scheme 12.

The key reaction is the diastereoselective acylation of ester 34 with the $\alpha, \beta$-unsaturated acid chloride 33. We predicted that the lithium enolate of compound $\mathbf{3 4}$ would coordinate with oxygen of the furan ring on the chiral $3 a$-hydroxyfuroindoline to make a rigid conformation and that diastereoselective acylation would occur, producing 32. Further, at the final stage, we expected that intramolecular acylation would occur with allylsilane compound 32, directly yielding (+)-madindolines A (+)-1 and B (+)-2. The chiral $3 a-$ hydroxyfuroindoline $(-)-\mathbf{4}$ is available as an enantiomerically pure substrate by asymmetric oxidative ring closing reaction of tryptophol $\mathbf{3}$, which was developed in the first-generation synthesis.

\subsection{Synthesis of $\mathbf{N}$-Alkyl-3a-Hydroxyfuroindoline Ester 34}

First, we started with the known compound $(+)-36^{29}$ to synthesize the enantiomerically pure aldehyde $(-)-35$, thus providing simple NMR spectra for all intermediates after the reductive amination sequence (Scheme 13). Pivaloyl protection of the hydroxy group of (+)-36 followed by acid hydrolysis of the TBS protection furnished alcohol (-)-37 in $84 \%$ yield for two steps. Next, (-)-37 was oxidized under Swern conditions to produce aldehyde (-)-35 in 93\% yield without epimerization at the $\alpha$-position. For material advancement on large-scale synthesis, we also prepared the racemic aldehyde $( \pm)-35$, because either epimer will generate the same enolate at the enolation stage of $\mathbf{3 4}$. Actually, $( \pm) \mathbf{- 3 5}$ was provided in high yield ( $76 \%$ for two steps) from the commercially available diol (士)-38 via mono pivaloyl protection and Swern oxidation.

Next, reductive amination ${ }^{30}$ of $3 \mathrm{a}$-hydroxyfuroindoline (-) $\mathbf{4}$ with aldehyde (-)-35 using acetic acid in dichloroethane, followed by iminium reduction with sodium triacetoxyboro-

sequence in $7.8 \%$ overall yield from commercially available materials.

\section{The Strategy for the Second-genaration Synthesis of (+)-Madindolines}

As described above, we have achieved the first total synthesis and determined the absolute stereochemistries of madindoloines $\mathrm{A}$ and $\mathrm{B}$. However, this first synthesis requires too many steps, especially for construction of the fully substi-

Scheme 12. Retrosynthetic analysis of (+)-madindolines A and B

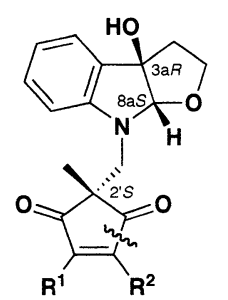

(+)-madindoline $\mathrm{A}(+)-1 ; \mathrm{R}^{1}=n-\mathrm{Bu} \mathrm{R}^{2}=\mathrm{Me}$ $(+)$-madindoline $\mathrm{B}(+)-2 ; \mathrm{R}^{1}=\mathrm{Me}, \mathrm{R}^{2}=n-\mathrm{Bu}$

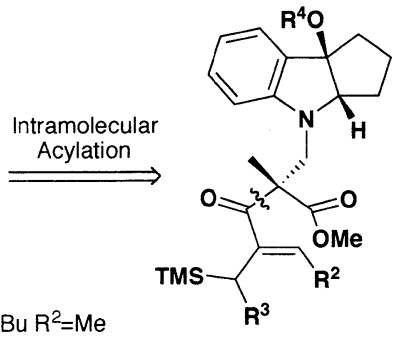

32a; $\mathrm{R}^{2}=\mathrm{Me}, \mathrm{R}^{3}=n-\mathrm{Pr}$ $32 \mathrm{~b} ; \mathrm{R}^{2}=n-\mathrm{Bu}, \mathrm{R}^{3}=\mathrm{H}$

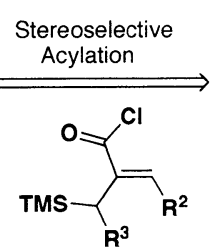

33a; $\mathrm{R}^{2}=\mathrm{Me}, \mathrm{R}^{3}=n-\mathrm{Pr}$ 33b; $R^{2}=n-B u, R^{3}=H$

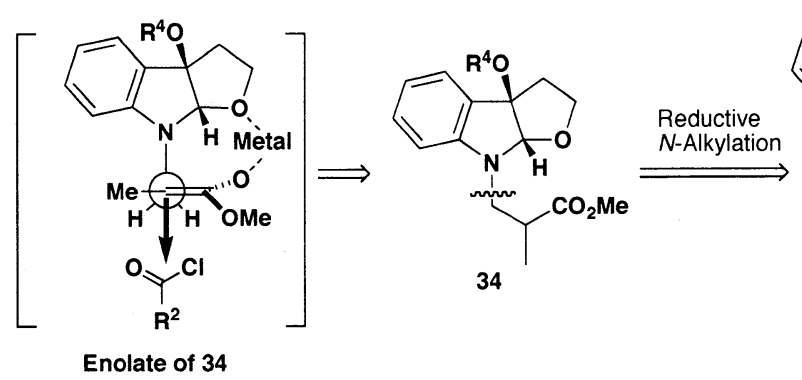


Scheme 13. Preparation of aldehyde $\mathbf{3 5}$

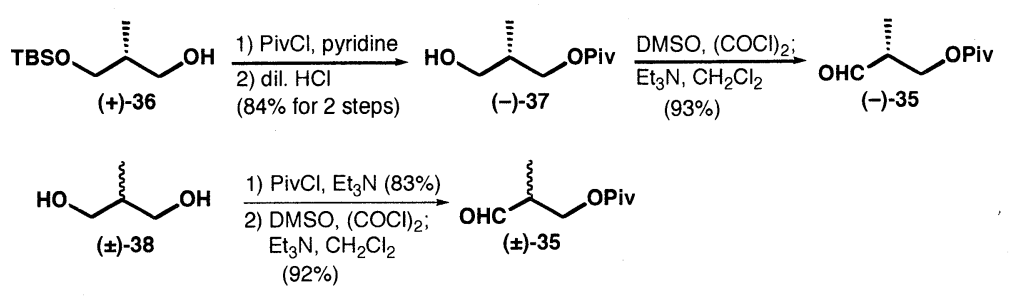

as a single diastereomer and enantiomer in $75 \%$ overall yield for the five steps. For material advancement, the same procedure was applied for the synthesis of a diastereomeric mixture of $\mathbf{3 4}$ starting from the racemic aldehyde ( \pm - -35 and $(-)-4$, which generated 34 in good yield.

\subsection{Construction of the Quaternary Car- bon Center in a Model System}

Reaction conditions to construct the required quaternary Scheme 14. Synthesis of methyl ester (-)-34

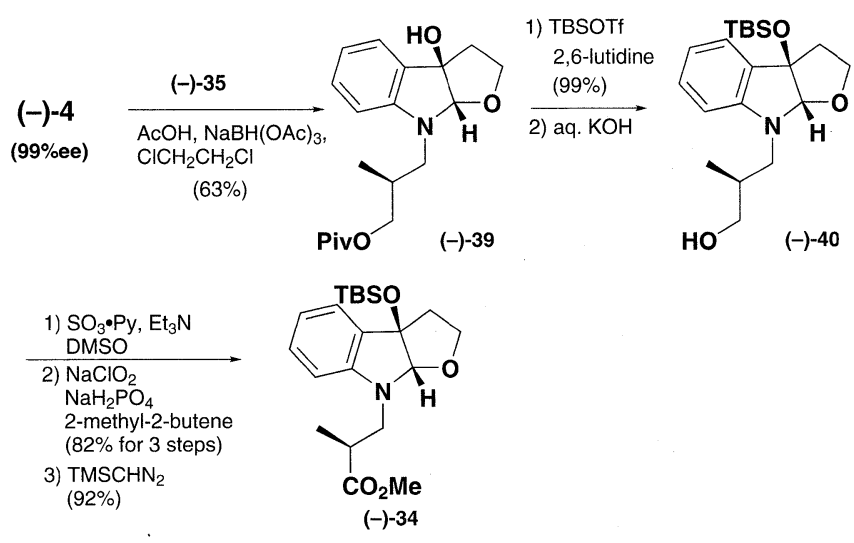

hydride $^{31}$ provided the desired $N$-alkyl-3a-hydroxyfuroindoline (-)-39 in 63\% yield in multi-gram scale (Scheme 14). Silylation of the tertiary alcohol with TBSOTf in the presence of 2,6-lutidine and hydrolysis of the pivaloyl ester under basic conditions generated the primary alcohol (-)-40. $\mathrm{SO}_{3} \cdot$ Pyridine oxidation of $(-) \mathbf{- 4 0}$ provided an aldehyde, followed by successive sodium chlorite oxidation and esterification using TMS-diazomethane furnished methyl ester (-)-34 carbon center were examined by coupling methacrolein 14, a simple aldol partner, to the methyl ester (-)-34 for confirming the selectivity and the generation of the enolate of $(-)-\mathbf{3 4}$, and the results are summarized in Table 2. To establish the conditions to form a rigid enolate (Scheme 12), we selected several kinds of metal amines as the base. The best result, high yield and high selectivity at the quaternary carbon center, was obtained using 2.5 equivalents of LDA (entry 3 ). On the other hand, KDA as a base (entry 5) or LDA with HMPA (entry 6) did not match this diastereoselective aldol reaction in terms of both chelation ability of the metal and basicity. In all cases, selectivity of the quaternary carbon center was determined by ${ }^{1} \mathrm{H}-\mathrm{NMR}$ measurements of the oxidation product $(\mathbf{- )} \mathbf{- 4 2}$. Based on our hypothesis of the enolate structure shown in Scheme 12, the configuration shown in Table 2 is expected to be produced predominantly as the stereochemistry of the quaternary center.

\subsection{Preparation of Aallylsilane 33}

Two kinds of allylsilanes (33a and 33b), were synthesized by practical methods (Scheme 15) as building blocks for $(+)-1$ and $(+)-2$. For a building block of (+)-2, alkylation of 43 with iodomethyltrimethylsilane, ${ }^{32}$ followed by the WittigHorner reaction ${ }^{33}$ with valeraldehyde led to the correspond-

Table 2. Diastereoselective aldol reaction for the construction of the quaternary carbon center

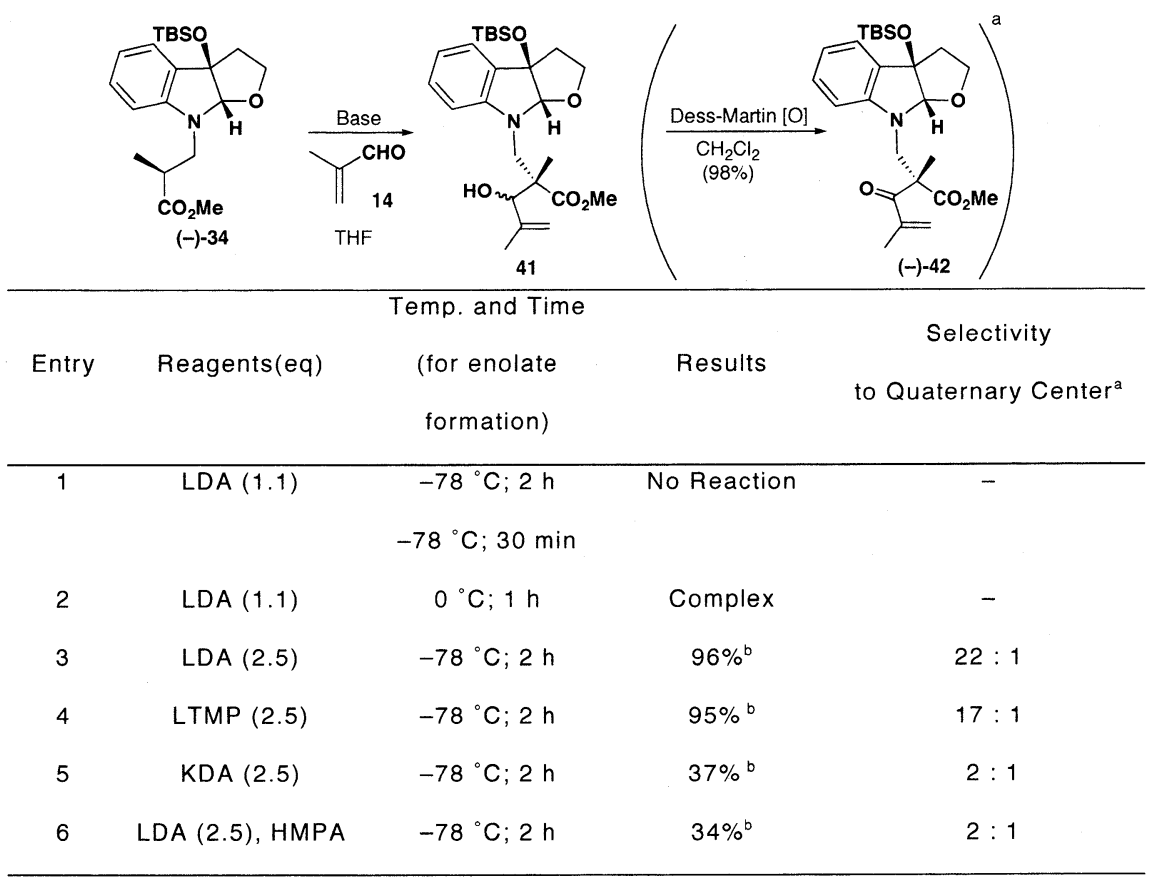

a Stereochemistry of the quaternary carbon was not determined, and the ratio of selectivity was elucidated by ${ }^{1} \mathrm{H}-\mathrm{NMR}$ measurements of the oxidized

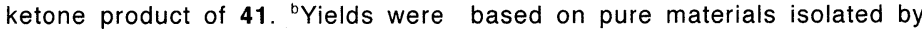
chromatography on $\mathrm{SiO}_{2}$. 
Scheme 15. Preparation of allylsilanes
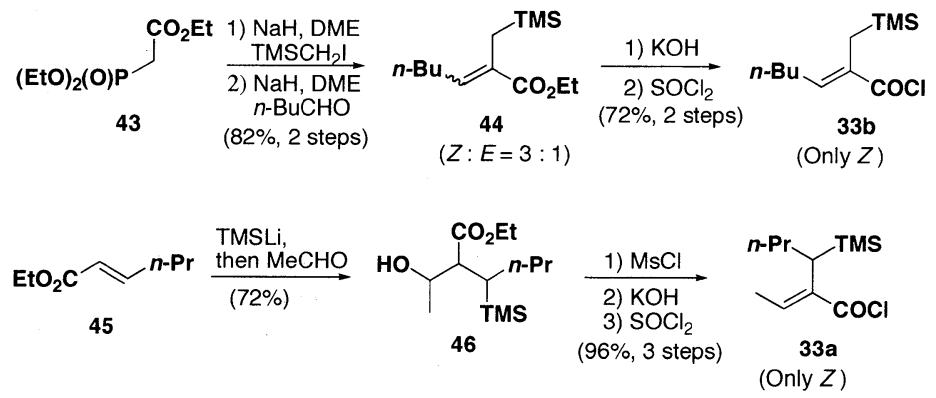

ing unsaturated ester 44 as a $3: 1=Z: E$ isomeric mixture in $82 \%$ yield for the two steps. Hydrolysis of ethyl ester 44, followed by chlorination with thionyl chloride generated $(Z)-\alpha$, $\beta$-unsaturated acid chloride $\mathbf{3 3 b}$ as a single isomer ${ }^{34}$ in $72 \%$ yield. For the synthesis of another allylsilane 33a, Michael addition of trimethylsilyl lithium to the ethyl 1-hexenoate $45,{ }^{35}$ followed by aldol reaction of the derived enolate with acetaldehyde produced the $\beta$-hydroxyester 46 in $72 \%$ yield as a diastereomeric mixture. Mesylation of $\mathbf{4 6}$, followed by basic hydrolysis resulted in the corresponding unsaturated acid, which was treated with thionyl chloride to afford the $(Z)-\alpha$, $\beta$-unsaturated acid chloride 33a as a single isomer ${ }^{34}$ in $96 \%$ yield for the three steps.

\subsection{Diastereoselective Acylation and Completion of the Synthesis}

The final stages of the synthesis involved diastereoselective acylation of ester $\mathbf{3 4}$ carrying a $3 \mathrm{a}$-hydroxyfuroindoline moiety with the acid chloride $\mathbf{3 3} \mathbf{a}-\mathbf{b}$ and intramolecular acylation promoted by allylsilane. The ester (-)-34 was treated with 2.5 eq. LDA followed by treatment with acid chloride 33b to afford the desired compound (-)-32b as a single isomer, in $99 \%$ yield (Scheme 16). The diastereomeric mixture of 34 for the $\alpha$-methyl group, which was prepared from racemic aldehyde $( \pm) \mathbf{- 3 5}$ by the same route as for $(-)-\mathbf{3 4}$, was also subjected to this reaction, and produced the desired (-)-32b as a single diastereomer in $99 \%$ yield. Finally, an intramolecular endo cyclization of allylsilane $(-\mathbf{- 3 2} \mathbf{b}$ using tris (dimethylamino)sulfur(trimethylsilyl)difluoride (TASF), ${ }^{36}$ directly led to $(+)$-madindoline $\mathrm{B}(+)-2$ in $56 \%$ yield. In addition, the absolute stereochemistry in (+)-2 was con-

Scheme 16. The end games for total synthesis of (+)-madindolines A and B

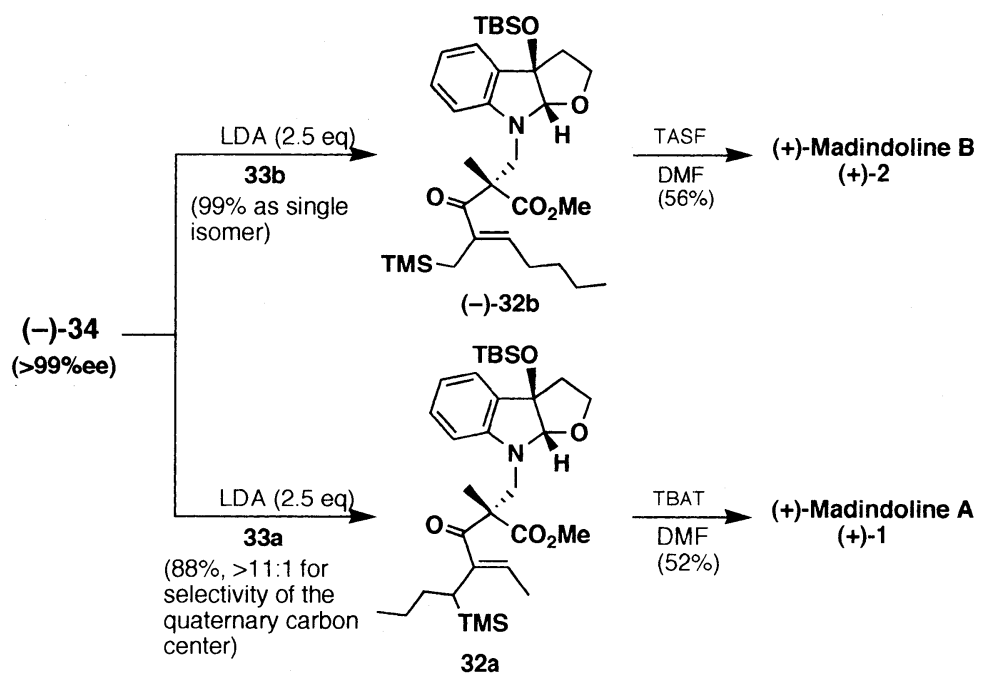

firmed by X-ray analysis of synthetic (+)-2.

On the other hand, in the total synthesis of $(+)$-madindoline A (+)-1, the stereoselective acylation of $(-) \mathbf{- 3 4}$ with acid chloride 33 a predominantly ( $>11: 1$ for selectivity of the quaternary carbon center) afforded the desired compound 32a in $88 \%$ yield. The diastereomeric mixture $\mathbf{3 4}$ also gave the desired 32a under the same conditions. The intramolecular endo cyclization of allylsilane 32a with triphenyldifluorosilicate (TBAT) ${ }^{37}$ directly led to $(+)$-madindoline $\mathrm{A}(+)-\mathbf{1}$ in $52 \%$ yield.

\section{Preparation of Tritiated (+)-Madindoline A $\left[{ }^{3} \mathrm{H}\right]-(+)-1$ and its Mode of Action}

Since madindolines are nonpeptidal low-molecular specific inhibitors of IL-6, studies on their action mechanism to IL-6 functions are expected to provide significant information about IL-6-dependent diseases as well as possible therapeutic uses of the compounds. After completion of the total syntheses of madindolines, we attempted the preparation of radioactively labeled madindoline $\mathrm{A}$ to facilitate the studies on its mode of action. ${ }^{37}$

We tested deuteration of (-) $\mathbf{- 2}$ with $\mathrm{D}_{2} \mathrm{O}$ under a basic condition, prior to the preparation of tritiated $(+)-\mathbf{1}$ with ${ }^{3} \mathrm{H}_{2} \mathrm{O}$. The results are summarized in Table 3 .

The conditions providing the highest deuteration rate with a good recovered yield were $\mathrm{NaOMe}$ in $\mathrm{CD}_{3} \mathrm{OD}$ or $0.5 \mathrm{~N}$ $\mathrm{KOH}$ in $t-\mathrm{BuOH} \cdot \mathrm{D}_{2} \mathrm{O}$ (entry 1 or 5 ). Therefore, we chose the conditions of entry 5 to prepare the tritiated madindoline $\mathrm{A}$ $\left(\left[{ }^{3} \mathbf{H}\right]-(+)-1442.8 \mathrm{Mb} / \mathrm{mmol}\right)$ as shown in Scheme 17. We revealed the binding site of $(+)-1$ in the complex of gp130, IL -6 and IL- 6 receptor (IL-6R) by the use of $\left[{ }^{3} \mathbf{H}\right]-(+)-1 .{ }^{38}$

In a dose-dependent manner $\left[{ }^{3} \mathbf{H}\right]-(+)-1$ binds to gp130, which is a signal transducing $130-\mathrm{kDa}$ glycoprotein, but formation of the trimeric complex IL-6/IL-6 receptor/gp130 was not inhibited, suggesting that MDL-A suppresses dimerization of trimeric complexes. Not only did MDL-A markedly inhibit IL-6- and IL-11-induced osteoclastogenesis in vitro, but it also inhibited IL-6-stimulated serum amyloid A production and bone resorption in an experimental model of postmenopausal osteoporosis in vivo by a different mechanism from that of $17 \beta$-estradiol. MDL-A has a highly selective inhibitory effect on IL-6 and IL-11 activities by inhibiting a gp130 activity while suppressing bone loss in ovariectomized mice. MDL-A is anticipated as a lead compound for treatment of hormone-dependent postmenopausal osteoporosis, which has no serious side effects, and as a new mechanism of action, gp130 blocking. IL-6 has three topological binding sites (sites I, II, and III) $39,40,41$, whereas gp130 has two binding sites (sites 1 and 2). ${ }^{42,43}$ IL-6 binds to the IL-6R via its site I and then to gp130 site 2 via site II, forming a trimeric IL-6/IL-6R/gp130 complex. ${ }^{39}$ The trimeric complex then induces homodimerization of gp130 and forms a hexameric complex. We found that (+)-1 binds to gp130 and inhibits the actions of IL-6 activity without inhibiting the formation of the IL-6/IL-6R/gp130 complex (Figure 5). ${ }^{38}$ 
Table 3. Deuteration of $(-)-\mathbf{2}$.

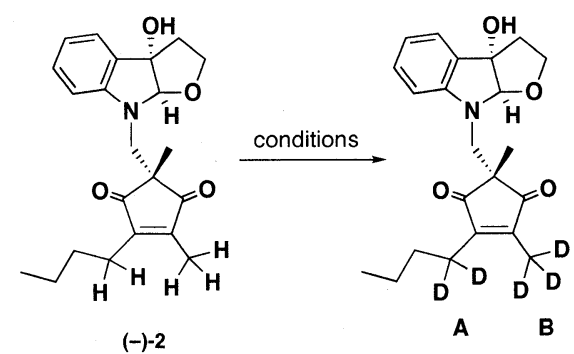

$(-)-2$

\begin{tabular}{|c|c|c|c|c|c|c|}
\hline \multirow{3}{*}{ Entry } & \multicolumn{6}{|c|}{$\left[{ }^{2} \mathrm{H}\right]-(-)-2$} \\
\hline & \multirow{2}{*}{ Reagents } & \multirow{2}{*}{ Temp. } & \multirow{2}{*}{ Time } & \multicolumn{2}{|c|}{ Deuteration rates ${ }^{a}$} & \multirow{2}{*}{$\begin{array}{c}\text { Recovered } \\
\text { yield }^{b}\end{array}$} \\
\hline & & & & A-position & B-position & \\
\hline 1 & $\mathrm{NaOMe}(20 \mathrm{eq})$ in $\mathrm{CD}_{3} \mathrm{OD}$ & r.t. & $7 \mathrm{~h}$ & $90 \%$ & $71 \%$ & $95 \%$ \\
\hline 2 & $\mathrm{NaOMe}(70 \mathrm{eq}), \mathrm{D}_{2} \mathrm{O}(50 \mathrm{eq})$ in $\mathrm{THF}$ & r.t. & $30 \mathrm{~min}$ & \multicolumn{2}{|c|}{-} & complex \\
\hline 3 & $0.5 \mathrm{~N} \mathrm{NaOD}$ in $\mathrm{MeOH} \cdot \mathrm{D}_{2} \mathrm{O}(3: 5)$ & r.t. & $22 \mathrm{~h}$ & $0 \%$ & $49 \%$ & $84 \%$ \\
\hline 4 & $1.0 \mathrm{~N} \mathrm{NaOD}$ in $\mathrm{MeOH} \cdot \mathrm{D}_{2} \mathrm{O}(3: 5)$ & r.t. & $22 \mathrm{~h}$ & $0 \%$ & $43 \%$ & $73 \%$ \\
\hline 5 & $0.5 \mathrm{~N} \mathrm{KOD}$ in $t-\mathrm{BuOH} \cdot \mathrm{D}_{2} \mathrm{O}(3: 5)$ & r.t. & $20 \mathrm{~h}$ & $86 \%$ & $63 \%$ & $71 \%$ \\
\hline
\end{tabular}

${ }^{a}$ The deuteration rate was determined by $1 \mathrm{H}-\mathrm{NMR}$, ${ }^{\mathrm{b}}$ The recovered yields were based on pure materials isolated by chromatography on $\mathrm{SiO}_{2}$.

Scheme 17. Preparation of $\left[{ }^{3} \mathrm{H}\right]-(+)$-madindoline A

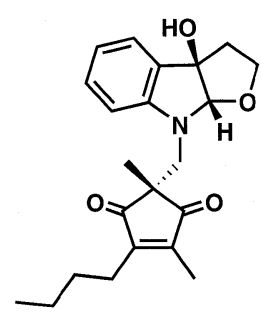

(+)-Madindoline A

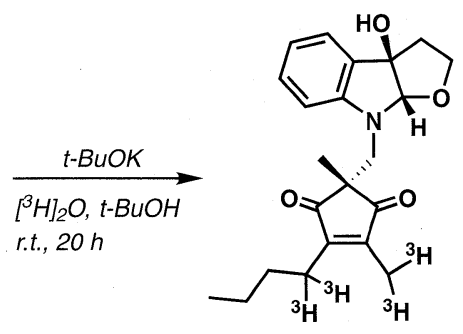

(+)-Madindoline A (442.8 Mb/mmol)

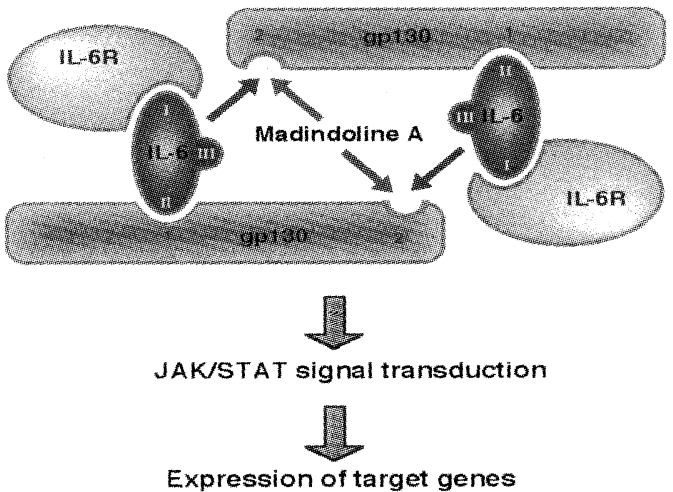

Figure 5

\section{Conclusion}

In summary, in the first-generation synthesis, we completed the first asymmetric total synthesis of madindolines A and B via an efficient and convergent strategy (19 linear steps, $7.8 \%$ overall yield). The synthetic route not only provides access to these unique natural products, but also enabled us to define their relative and absolute stereochemistries for the first time. In the second-generation synthesis, we achieved a highly convergent total synthesis of (+)-madindolines $\mathrm{A}$ and $\mathrm{B}$ by exploiting the $3 \mathrm{a}$-hydroxyfuroindoline function to per- mit rapid and efficient construction of the quaternary carbon center of madindolines with high selectivity. Importantly, the syntheses of (+)-1 and 2 are highly efficient, proceeding in $16 \%$ and $19 \%$ overall yield for 9 linear steps, respectively, stereocontrolled, and amenable to gram-scale production.

We also confirmed that synthetic (+)-madindoline A (+)-1 markedly inhibited osteoclastogenesis in vitro and inhibited bone resorption in OVX mice in vivo, and the use of tritiated $\left[{ }^{3} \mathrm{H}\right]-(+)$-madindoline A revealed the mode of action for manifestation of inhibitory activity. We believe that madindolines can serve as lead compounds for development of new drugs to treat refractory diseases known to involve IL-6.

\section{Acknowledgments}

We are grateful to Drs. Kanki Komiyama and Masahiko Hayashi for their great contribution to the discovery of interesting bioactive natural products, and also Professors Amos B. Smith, III, and Isao Kuwajima for their helpful suggestions. We would also like to thank Messrs. Daisuke Yamamoto, Naoto Kojima, Tatsuya Shirahata, Kiminari Yoshida, and Ms. Ayako Endo for their admirable experimental efforts. This work was supported in part by a Grant of the $21^{\text {st }}$ Century COE Program, Ministry of Education, Culture, Sports, Science and Technology (MEXT), The Japan Science and Technology Corporation (JST), a Grant-in-Aid for Scientific Research from the Ministry of Education, Science, Sports and Culture, Japan and the Japan Keirin Association and a Kitasato University Research Grant for Young Researchers (T. S.). We also thank the JSPS for a predoctoral fellowship to T. H.

\section{References and notes}

1) Ōmura, S. The Search for Bioactive Compounds from Microor- 
ganisms. Brock/Springer Series in Contemporary Biosciences. Springer-Verlag, New York, 1992

2) Ömura, S. Splendid Gifts from Microorganisms. $3^{\text {rd }}$ ed., The Kitasato Inst. and Kitasato Inst. for Life Sciences, Kitasato Univ., 2003

3) (a) Kishimoto, T.; Akira, S.; Taga, T. Science 1992, 258, 593. (b) Hirano, T. Int. Rev. Immunol. 1998, 16, 249

4) Strassmann, G.; Masui, Y.; Chizzonite, R.; Fong, M. J. Immunol. 1993, 150, 2341.

5) Yoshizaki, K.; Matsuda, T.; Nishimoto, N.; Kuritani, T.; Taeho, L.; Aozasa, K.; Nakahata, T.; Kawai, H.; Tagoh, H.; Komori, T.; Kishimoto, S.; Hirano, T.; Kishimoto, T. Blood 1989, 74, 1360

6) Takagi, N.; Mihara, M.; Moriya, Y.; Nishimoto, N.; Yoshizaki, K.; Kishimoto, T.; Takeda, Y.; Ohsugi, Y. Arthritis Rheum. 1998, 41, 2117.

7) de la Mata, J.; Uy, H. L.; Guise, T. A.; Story, B.; Boyce, B. F.; Mundy, G. R.; Roodman, G. D. J. Clin. Invest. 1995, 95, 28462852.

8) Zhang, X. G.; Bataille, R.; Jourdan, M.; Saeland, S.; Banchereau, J.; Mannoni, P.; Klein, B. Blood 1990, 76, 2599.

9) Lutticken, C.; Wegenka, U. M.; Yuan, J.; Buschmann, J. Schindler, C.; Ziemiecki, A.; Harpur, A. G.; Wilks, A. F.; Yasukawa, K.; Taga, T.; Kishimoto, S.; Barbieri, G.; Pellegrini, S.; Sendtner, M.; Heinrich, P. C.; Horn, F. Science 1994, 263, 89.

10) Hayashi, M.; Kim, Y.-P.; Takamatsu, S.; Enomoto, A.; Shinose, M.; Takahashi, Y.; Tanaka, H.; Komiyama, K.; Ömura, S. J. Antibiot. 1996, 49, 1091.

11) Takamatsu, S.; Kim, Y.-P.; Enomoto, A.; Hayashi, M.; Tanaka, H.; Komiyama, K.; Ōmura, S. J. Antibiot. 1997, 50, 1069

12) (a) Sunazuka, T.; Hirose, T.; Shirahata, T. Harigaya, Y.; Hayashi, M.; Komiyama, K.; Ōmura, S.; Smith, A. B., III. J. Am. Chem. Soc. 2000, 122, 2122. (b) Hosokawa, S.; Sekiguchi, K.; Enemoto, M.; Kobayashi, S. Tetrahedron Lett. 2000, 41, 6429. (c) Hosokawa, S.; Sekiguchi, K.; Hayase, K.; Hirukawa, Y.; Kobayashi, S. Tetrahedron Lett. 2000, 41, 6435. (d) Hosokawa, S.; Kobayashi, S. J. Synth. Org. Chem. Jpn. 2001, 59, 1103. (e) Hirose, T.; Sunazuka, T.; Shirahata, T.; Yamamoto, D.; Harigaya, Y.; Kuwajima, I.; Ōmura, S. Org. Lett. 2002, 4, 501. (f) McComas, C. C.; Perales, J. B.; Van Vranken, D. L. Org. Lett. 2002, 4, 2337. (g) Hirose, T.; Sunazuka, T.; Yamamoto, D.; Kojima, N.; Shirahata, T.; Harigaya, Y.; Kuwajima, I.; Ömura, S. Tetrahedron 2005, 61, in press

13) Katsuki, T.; Sharpless, K. B. J. Am. Chem. Soc. 1980, 102, 5974.

14) Racemic 3a-hydroxyfuroindoline $( \pm)^{-4}$ had been prepared previously by photosensitized oxygenation of tryptophol 3; see: Saito, I.; Imuta, M.; Nakada, A.; Matsugo. S.; Matsuura, T. Photochemistry and Photobiology 1978, 28, 531 and references cited therein.

15) Lance C. F. Synthesis 1975, 135 and references cited therein.

16) Flaugh, M. E.; Mullen, D. L.; Fuller, R. W.; Mason, N. R. J. Med. Chem. 1988, 31, 1746.

17) White, W. A.; Weingarten, H. J. Org. Chem. 1967, 32, 213.
18) (a) Schuster, M.; Blechert, S. Angew. Chem. Int. Ed. Engl. 1997 36, 2036 and references cited therein. (b) Grubbs, R. H.; Chang, S. Tetrahedron 1998, 54, 4413. (c) Armstrong, S. K. J. Chem. Soc. Perkin Trans. I 1998, 371.

19) Evans, D. A.; Kaldor, S. W.; Jones, T. K.; Clardy, J.; Stout, T. J. J. Am. Chem. Soc. 1990, 112, 7001 .

20) The absolute stereochemistry of 17 was randomly selected.

21) Fráter, G.; Müller, U.; Günther, W. Tetrahedron 1984, 40, 1269.

22) Gelas, J.; Horton, D. Heterocycles 1981, 16, 1587.

23) Leblanc, Y.; Fitzsimmons, B. J.; Adams, J.; Perez, F.; Rokach, J. J. Org. Chem. 1986, 51, 789

24) Borrelly, S.; Paquette, L. A. J. Am. Chem. Soc. 1996, 118, 727.

25) (a) Grieco, P. A.; Nishizawa, M.; Marinovic, N.; Ehmann, W. J. J. Am. Chem. Soc. 1976, 98, 7102. (b) Clive, D. L. J.; Joussef, A. C. J. Org. Chem. 1990, 55, 1096.

26) Dess, D. B.; Martin, J. C. J. Org. Chem. 1983, 48, 4155.

27) Luche, J.-L. J. Am. Chem. Soc. 1978, 100, 2226.

28) Braish, T. F.; Fuchs, P. L. Synth. Commun. 1986, 16, 111.

29) (a) Marshall J. A.; Trometer J. D. Tetrahedron Lett. 1987, 28 , 4985. (b) Mori, K.; Koseki, K. Tetrahedron 1988, 44, 6013.

30) Michael addition of $(-)-\mathbf{4}$ to methyl methacrylate or acrylate to afford $\mathbf{3 4}$ was unsuccessful under several conditions.

31) Ramanjulu, J. M.; Joullié, M. M. Synth. Commun. 1996, 26, 1379 .

32) Hosomi, A.; Hashimoto, H.; Sakurai, H. Tetrahedron Lett. 1980 , 21,951 .

33) Martin, H.; Hoffmann, R.; Rabe, J. J. Org. Chem. 1985, 50, 3849 .

34) Because $(E)$-isomers changed to more thermodynamically stable $(Z)$-isomers during the reactions.

35) Still, W. C. J. Org. Chem. 1985, 41, 3063

36) (a) Fujita, M.; Obayashi, M.; Hiyama, T. Tetrahedron 1988, 44, 4135. (b) Scheidt, K. A.; Chen, H.; Follows, B. C.; Chemler, S. R.; Coffey, D. S.; Roush, W. R. J. Org. Chem. 1998, 63, 6436.

37) (a) Pilcher, A. S.; DeShong, P. J. Org. Chem. 1996, 61, 6901. (b) Pilcher, A. S.; Ammon, H. L.; DeShong, P. J. Am. Chem. Soc. 1995, 117, 5166

38) Hayashi, M.; Rho, M.-C.; Enomoto, A.; Fukami, A.; Kim. Y.-P.; Kikuchi, Y.; Sunazuka, T.; Hirose, T.; Komiyama,K.; Omura, S. Proc. Natl. Acad. Sci. USA 2002, 99, 14728.

39) Ciapponi, L.; Graziani, R.; Paonessa, G.; Lahm, A.; Ciliberto, G.; Savino, R. J. Biol. Chem. 1995, 270, 31249.

40) Paonessa, G.; Graziani, R.; De Serio, A.; Savino, R.; Ciapponi, L.; Lahm, A.; Salvati, A. L.; Toniatti, C.; Ciliberto, G. EMBO J. 1995, 14, 1942.

41) Barton, V. A.; Hall, M. A.; Hudson, K. R.; Heath, J. K. J. Biol. Chem. 2000, 275, 36197.

42) Barton, V. A.; Hudson, K. R.; Heath, J. K. J. Biol. Chem. 1999 $274,5755$.

43) Kurth, I.; Horsten, U.; Pflanz, S.; Dahmen, H.; Kuster, A.; Grotzinger, J.; Heinrich, P. C.; Muller-Newen, G. J. Immunol. $1999,162,1480$. 


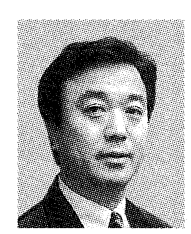

Toshiaki Sunazuka is Professor of Kitasato Institute for Life Sciences, and Graduate School of Infection Control Sciences at Kitasato University, and Visiting Director at The Kitasato Institute. He was born in Chiba, Japan in 1959, and received his $\mathrm{Ph}$. D. under the supervision of Professor S. Ōmura at School of Pharmaceutical Science at Kitasato University (1988). After working as a postdoctoral fellow (1988-1990) at University of Pennsylvania with Professor A. B. Smith, III, he joined The Kitasato Institute as a Senior Researcher. He was appointed Assistant Professor, Kitasato University, in 1994 and promoted to an Associate Professor in 2002, and Professor in 2005. He received the Progress Award in Synthetic Organic Chemistry, Japan, and the Sumiki-Umezawa Award. His research interests are in the areas of synthetic organic chemistry, medicinal, and bioorganic chemistry of bioactive natural products.

Tomoyasu Hirose is a postdoctoral fellow of The Kitasato Institute. He was born in Kanagawa in 1973 and received his B. Sc. (1996) and Ph.D. degree (2001) from Kitasato University. After working as a postdoctoral fellow (2001-2003) at University of Pennsylvania with Professor Amos B. Smith, III, he joined The Kitasato Institute as a postdoctoral fellow in 2003. In 2004, he received the Inoue Research Award for Young Scientists. His research interests are in the areas of synthetic organic chemistry, medicinal, and bioorganic chemistry.
Satoshi Ōmura is Professor and President of The Kitasato Institute, Professor of Kitasato Institute for Life Sciences and Graduate School of Infection Control Sciences, Kitasato University. He was born in Yamanashi Prefecture, Japan, in 1935 and received his Ph.D. in Pharmaceutical Sciences from the University of Tokyo in 1968 and in Chemistry from Tokyo University of Science, in 1970. He was appointed Professor of School of Pharmaceutical Sciences, Kitasato University, in 1975 . He has been the President of The Kitasato Intitute since 1990. His research interests focus on chemistry and biology of microbial metabolites, including discovery; the biosynthesis and hybrid biosynthesis of new macrolide antibiotics; the breeding, genetic analysis and mapping of Streptomyces avermectinius; synthesis of the novel semi-synthetic macrolides; the organic synthesis of new compounds. He was a recipient of the Japan Academy Prize (1990), ACS Nakanishi Prize (2000), ACS Ernest Guenther Award in the Chemistry of Natural Products (2005), and many other awards at home and abroad. He is a member of Deutsche Akademie der Naturforscher "Leopoldina" (Germany) (1992), National Academy of Sciences, USA (1999), the Japan Academy (2001), Institut de France, Academie des Sciences (2002), Russian Academy of Sciences (2004), and European Academy of Sciences (2005). 